\title{
Sistem Pendukung Keputusan Dalam Memilih Bibit Jambu Madu Terbaik Dengan Menggunakan Metode Moora dan SAW
}

\author{
Agung Pradana, Yuyun Dwi Lestari, Mufida Khairani \\ Universitas Harapan, Medan, Indonesia $1,2,3$ \\ Email : agungpradana100@gmail.com ${ }^{1}$, yuyun.dl@ gmail.com ${ }^{2}$, \\ mufida.khairani@gmail.com ${ }^{3}$
}

\begin{abstract}
Abstrak
Jambu madu merupakan jambu yang memiliki tingkat kemanisan yang luar biasa. Namun tidak mudah untuk memilih bibit jambu madu yang baik dan berkualitas. Bibit jambu yang kurang bagus dapat menyebabkan pertumbuhan yang lambat, sehingga panen jambu madu akan terhambat dan lama untuk panen. Dengan memilih bibit jambu yang baik dan berkualitas dapat menjamin hasil yang sangat memuaskan, sehingga hasil panen tidak terlalu lama dan meningkatkan keuntungan yang lebih besar. Sistem pendukung keputusan ini diharapkan dapat membantu penjual dalam menentukan bibit jambu madu yang terbaik. Pada penelitian ini dibuat dengan menggunakan metode Multi-Objective Optimization on the Basis of Ratio Analysis (MOORA) dan metode Simple Additive Weighting (SAW). Berdasarkan hasil dari pengerjaan metode MOORA dan metode SAW didapatkan hasil yang sama dimana setiap alternatif mendapatkan urutan dan rangking yang sama dengan nilai yang berbeda.
\end{abstract}

Kata Kunci : Jambu Madu, Sistem Pendukung Keputusan, Metode MOORA, Metode SAW

\begin{abstract}
Honey guava is a guava that has an extraordinary level of sweetness. But it is not easy to choose good and quality honey guava seeds. Poor guava seeds can cause slow growth, so that the honey guava harvest will be hampered and take a long time to harvest. Choosing good and quality guava seeds can guarantee very satisfying results, so that the harvest will not take too long and increase greater profits. This decision support system is expected to assist the seller in determining the best guava seeds. This research was made using the Multi-Objective Optimization method on the Basis of Ratio Analysis (MOORA) and the Simple Additive Weighting (SAW) method. Based on the results of working with the MOORA method and the SAW method, the same results were obtained where each alternative got the same order and ranking with different values.
\end{abstract}

Keywords: Honey Guava, Decision Support System, MOORA Method, SAW Method 


\section{PENDAHULUAN}

Perkembangan teknologi saat ini telah mengalami banyak perubahan yang sangat pesat, dalam dunia kerja teknologi memiliki peran yang sangat penting, hampir seluruh aspek semuanya membutuhkan teknologi dalam menyelesaikan masalah misalnya: bisnis, pendidikan, kesehatan, pertanian dan lain sebagainya. Dalam dunia pertanian, teknologi dibutuhkan untuk memilih bibit yang baik dan berkualitas.

Jambu madu merupakan jambu yang sangat menguntungkan untuk di jual, karena itu banyak yang ingin menanam jambu madu untuk di jual ataupun untuk dimakan sendiri. Namun tidak mudah untuk memilih bibit jambu madu yang baik dan berkualitas. Bibit jambu yang kurang bagus dapat menyebabkan pertumbuhan yang lambat, sehingga panen jambu madu akan terhambat dan lama untuk dipanen. Dengan memilih bibit jambu yang baik dan berkualitas dapat menjamin hasil yang sangat memuaskan. Sehingga hasil panen tidak terlalu lama dan meningkatkan keuntungan yang lebih besar.

Sistem pendukung keputusan (SPK) merupakan suatu sistem yang mampu untuk memutuskan atau menyelesaikan masalah dengan mesin atau komputer. Dengan adanya sistem pendukung keputusan untuk menentukan kualitas bibit jambu madu terbaik dengan menggunakan metode MOORA dan metode SAW, untuk mengetahui hasil dari kedua metode tersebut, sehingga dapat menentukan kualitas bibit jambu madu secara cepat dan tepat.

\section{LANDASAN TEORI}

\section{a. Sistem Pendukung Keputusan}

Sistem pendukung keputusan adalah suatu sistem yang digunakan untuk menyelesaikan masalah, Saling bertukar informasi antara sistem dan pemakai untuk memecahkan masalah tertentu dengan terstruktur maupun tidak terstruktur. [1]

Definisi lain menurut [2], Sistem pendukung keputusan merupakan sebuah sistem yang menghubungkan komputer dan informasi dengan pemakai sebagai pengambil keputusan. Dengan demikian sistem pendukung keputusan adalah seperangkat data atau model yang digabungkan menjadi satu yang saling bekerja sama untuk mendapatkan hasil dan tujuan bersama. Untuk menghasilkan keputusan yang baik di dalam sistem pendukung keputusan, perlu didukung oleh informasi dan fakta-fakta yang berkualitas.

\section{b. Metode Multi-Objective Optimization On The Basis Of Ratio Analysis (MOORA)}

Metode Multi-Objective Optimization On The Basis Of Ratio Analysis (MOORA) merupakan metode pengambilan keputusan yang diperkenalkan oleh Brauers dan Zavadkas (2006). Dengan menggunakan pendukung keputusan multi-Kriteria Brauers (2003). Pengambilan keputusan memiliki beberapa bidang yang menggunakan metode MOORA yaitu bidang ekonomi, manajemen, kontraktor, bangunan dan desain jalan. Metode MOORA memiliki nilai selektifitas yang baik dalam menentukan sebuah alternatif dan dapat menentukan tujuan dan kriteria yang bertentangan, yaitu kriteria yang bernilai menguntungkan (Benefit) atau yang tidak menguntungkan (Cost).[3]

Langkah - langkah untuk menyelesaikan masalah menggunakan metode MOORA yaitu:[4]

1. Menentukan arah tujuan untuk mengidentifikasi atribut dari evaluasi yang bersangkutan.

2. Membuat matriks keputusan

$$
\mathrm{Xij}=\left[\begin{array}{cccc}
x_{11} & x_{12} & \cdot & x_{1 n} \\
x_{21} & x_{22} & * & x_{2 n} \\
- & \cdot & \cdot & \cdot \\
x_{m 1} & x_{m 2} & \cdot & x_{m n}
\end{array}\right]
$$


Menentukan Normalisasi Matriks Keputusan

$$
x_{i j}^{*}=\frac{x_{i j}}{\sqrt{\sum_{i=1}^{m} x^{2} i j}}
$$

Brauers (2008) menyimpulkan bahwa untuk penyebut ini, pilihan terbaik dari akar kuadrat dari penjumlahan kuadrat setiap alternatif dibagi perkriteria.

3. Menentukan Matriks Normalisasi Terbobot

$$
y_{i}=\sum_{j=1}^{g} W j x i j *-\sum_{j=g+1}^{n} W j x i j^{*}
$$

Dimana $\mathrm{Wj}$ adalah bobot dari kriteria yang telah ditentukan.

4. Menentukan Nilai Preferensi

$$
y_{i}=\sum_{j=1}^{g} W j x^{*} i j-\sum_{i=g+1}^{n} w j x^{*} i j(\mathrm{j}=1,2, \mathrm{n})
$$

Didapatkan alternatif terbaik memiliki nilai yi tertinggi, sedangkan alternatif terburuk memiliki nilai yi terendah.

\section{c. Metode Simple Additive Weighting (SAW)}

Metode Simple Additive Weighting (SAW) sering juga dikenal istilah metode penjumlahan terbobot. Konsep dasar metode SAW adalah mencari penjumlahan terbobot dari rating kinerja pada setiap alternatif pada semua atribut. Metode SAW membutuhkan proses normalisasi matriks keputusan (X) ke suatu skala yang dapat diperbandingkan dengan semua rating alternatif yang ada.[5]

Adapun Langkah-langkah penyelesaian metode SAW sebagai berikut:[6]

1. Menentukan kriteria-kriteria yang akan dijadikan acuan dalam pengambilan keputusan.

2. Menentukan rating kecocokan setiap alternatif pada setiap kriteria.

3. Membuat matriks keputusan berdasarkan kriteria, kemudian melakukan normalisasi matriks berdasarkan persamaan yang disesuaikan dengan jenis atribut keuntungan ataupun atribut biaya.

$$
r_{i j}=\left\{\begin{array}{cl}
\frac{x_{i j}}{\operatorname{Max}\left(x_{i j}\right)} & \text { jika j adalah atribut keuntungan } \\
\frac{\operatorname{Min}_{i}\left(x_{i j}\right)}{x_{i j}} & \text { jika j adalah atribut biaya }
\end{array}\right.
$$

4. Hasil akhir diperoleh dari proses perangkingan yaitu penjumlahan dari perkalian matriks normalisasi dengan bobot kriteria.

$$
\mathrm{Vi}=\sum_{j=1}^{n} w_{j} r_{i j}
$$

d. Jambu Madu

Jambu madu merupakan jambu yang memiliki kemanisan yang luar biasa, tingkat kemanisan jambu madu dapat mengalahkan kemanisan buah apel dan buah lainnya. Adapun Jenis-jenis jambu madu menurut bapak Anton ada tiga jenis jambu madu yaitu :

1. Jambu Madu Deli Hijau

Jambu madu deli hijau merupakan jambu madu termanis diantara jambu madu lainnya, karena jambu madu deli hijau memiliki tingkat kemanisan yang sangat tinggi dan juga memiliki daging yang rapuh sehingga sangat enak saat dimakan. Perbedaan diantara jambu madu lainnya adalah jambu madu deli hijau mampu menghasilkan buah yang lebih banyak walau memiliki ukuran yang jauh lebih kecil. Jambu madu deli hijau memiliki sifat yang cepat berbuah.

2. Jambu Madu Kesuma Merah

Jambu madu kesuma merah merupakan jambu madu air yang berwarna merah. Jambu madu kesuma merah memiliki daging yang tebal dan hampir tidak memiliki lubang biji. Jambu kesuma merah memiliki waktu yang cukup lama berbuahnya sekitaran usia 13- 
15 bulan. Dikarenakan pohon jambu madu kesuma merah lebih besar dibandingkan pohon jambu madu deli hijau.

\section{METODE PENELITIAN}

1. Identifikasi Masalah

Pada tahapan ini penulis melakukan identifikasi terhadap masalah yang akan dibahas dan metode yang akan digunakan untuk menyelesaikan permasalahan.

2. Analisa Permasalahan

Pada tahap ini penulis melakukan analisa masalah terhadap masalah yang akan dibahas, sehingga masalah dapat dipahami dengan baik

3. Studi Literatur

Melakukan studi literatur untuk melihat apakah teori yang sudah dimiliki dapat dikembangkan serta mendapatkan landasan teori yang sesuai mengenai masalah dan metode yang diteliti.

4. Mengumpulkan Data Yang Dibutuhkan

Melakukan pengumulan data yang diperlukan untuk menunjang penelitian.

5. Menganalisis Data dan Metode

Pada tahap ini dilakukan analisis terhadap data-data dan menerapkannya pada metode yang digunakan sesuai dengan kriteria-kriterianya.

6. Implementasi Metode

Pada tahap ini dilakukan implementasi metode terhadap sampel data yang digunakan

7. Menetapkan Kesimpulan

Pada tahap ini dilakukan kesimpulan dari penerapan metode terhadap sampel data yang digunakan agar mendapatkan sebuah pengambilan keputusan.

\section{Hasil dan Pembahasan}

\section{a. Kriteria Sistem Pendukung Keputusan Metode MOORA}

Ada 5 Sampel bibit jambu madu yang akan menjadi Alternatif yaitu sampel $1=\mathrm{A} 1$, sampel 2=A2, sampel 3=A3, sampel 4=A4, sampel 5=A5. Dan 4 kriteria yang akan dijadikan acuan dalam pengambilan keputusan yaitu:

$\mathrm{C} 1=$ Tekstur Tanah, C2 = Bentuk Batang, C3 = Bentuk Daun, C4 = Tinggi Tanaman .

Tabel 4.1 Tekstur Tanah

\begin{tabular}{|l|c|}
\hline Ket & Bobot \\
\hline Tanah Berpasir & 1 \\
\hline Tanah Berpasir Berlempung & 2 \\
\hline Tanah Lempung Halus & 3 \\
\hline
\end{tabular}

Tabel 4.2 Bentuk Batang

\begin{tabular}{|l|c|}
\hline Ket & Bobot \\
\hline Kecil (0-3) mm & 1 \\
\hline Sedang (4-6) mm & 2 \\
\hline Besar (7-10) mm & 3 \\
\hline
\end{tabular}

Tabel 4.4 Tinggi Tanaman

\begin{tabular}{|l|c|}
\hline Ket & Bobot \\
\hline Rendah (0-9) cm & 1 \\
\hline Sedang (10-19) cm & 2 \\
\hline Tinggi $(20-30) \mathrm{cm}$ & 3 \\
\hline
\end{tabular}

Tabel 4.6 Tabel Pembobotan Kriteria

Tabel 4.5 Pembobotan

\begin{tabular}{|l|l|l|l|}
\hline Kriteria & Keterangan & Bobot & Jenis \\
\hline C1 & Tekstur Tanah & $10 \%$ & Benefit \\
\hline C2 & Bentuk Batang & $30 \%$ & Benefit \\
\hline C3 & Bentuk Daun & $20 \%$ & Benefit \\
\hline
\end{tabular}




\section{\begin{tabular}{l|l|l|l|}
\hline C4 & Tinggi Tanaman & $40 \%$ & Benefit \\
\hline
\end{tabular}}

Matriks Keputusan Metode MOORA

$$
X\left[\begin{array}{llll}
3 & 2 & 3 & 2 \\
3 & 3 & 2 & 2 \\
3 & 1 & 3 & 2 \\
3 & 3 & 3 & 3 \\
3 & 2 & 2 & 1
\end{array}\right]
$$

\begin{tabular}{|c|c|c|c|c|}
\hline Alternatif & C1 & C2 & C3 & C4 \\
\hline Sampel 1 & 3 & 2 & 3 & 2 \\
\hline Sampel 2 & 3 & 3 & 2 & 2 \\
\hline Sampel 3 & 3 & 1 & 3 & 2 \\
\hline Sampel 4 & 3 & 3 & 3 & 3 \\
\hline Sampel 5 & 3 & 2 & 2 & 1 \\
\hline
\end{tabular}

Kemudian melakukan normalisasi matriks dengan menggunakan persamaan 2.

$\mathrm{C} 1$

$$
\begin{aligned}
& =\sqrt{3^{2}+3^{2}+3^{2}+3^{2}+3^{2}} \\
& =\sqrt{9+9+9+9+9} \\
& =\sqrt{45}=6,708
\end{aligned}
$$

$\mathrm{A}_{11}=3 / 6,708=0,447$

$\mathrm{A}_{21}=3 / 6,708=0,447$

$\mathrm{A}_{31}=3 / 6,708=0,447$

$\mathrm{A}_{41}=3 / 6,708=0,447$

$\mathrm{A}_{51}=3 / 6,708=0,447$

$$
\begin{aligned}
\mathrm{C} 3 & =\sqrt{3^{2}+2^{2}+3^{2}+3^{2}+2^{2}} \\
& =\sqrt{9+4+9+9+4} \\
& =\sqrt{35}=5,916 \\
\mathrm{~A}_{13}=3 & / 5,916=0,507
\end{aligned}
$$$$
\mathrm{A}_{23}=2 / 5,916=0,338
$$$$
\mathrm{A}_{33}=3 / 5,916=0,507
$$$$
\mathrm{A}_{43}=3 / 5,916=0,507
$$$$
\mathrm{A}_{53}=2 / 5,916=0,338
$$

C2

$$
\begin{aligned}
& =\sqrt{2^{2}+3^{2}+1^{2}+3^{2}+2^{2}} \\
& =\sqrt{4+9+1+9+4} \\
& =\sqrt{27}=5,196 \\
& A_{12}=2 / 5,196=0,384 \\
& A_{22}=3 / 5,196=0,577 \\
& A_{32}=1 / 5,196=0,192 \\
& A_{42}=3 / 5,196=0,577 \\
& A_{52}=2 / 5,196=0,384
\end{aligned}
$$

$$
\begin{array}{ll}
\mathrm{C} 4 & =\sqrt{2^{2}+2^{2}+2^{2}+3^{2}+1^{2}} \\
& =\sqrt{4+4+4+9+1} \\
& =\sqrt{22}=4,690 \\
& \mathrm{~A}_{14}=2 / 4,690=0,426 \\
& \mathrm{~A}_{24}=2 / 4,690=0,426 \\
& \mathrm{~A}_{34}=2 / 4,690=0,426 \\
& \mathrm{~A}_{44}=3 / 4,690=0,639 \\
& \mathrm{~A}_{54}=1 / 4,690=0,213
\end{array}
$$

Matriks Normalisasi Terbobot:

Matriks normalisasi :

$$
\mathrm{X} * \text { ij }\left[\begin{array}{cccc}
0,447 & 0,384 & 0,507 & 0,426 \\
0,447 & 0,577 & 0,338 & 0,426 \\
0,447 & 0,192 & 0,507 & 0,426 \\
0,447 & 0,577 & 0,507 & 0,639 \\
0,447 & 0,384 & 0,338 & 0,213
\end{array}\right]
$$

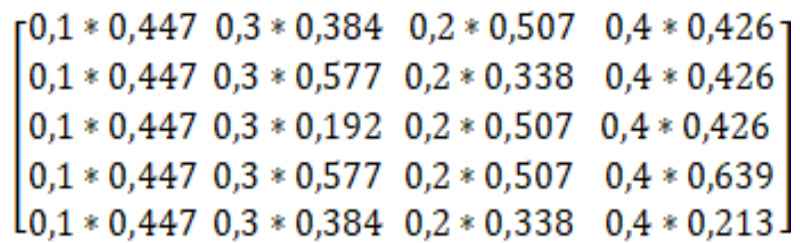

Hasil setelah dihitung:

$\left[\begin{array}{llll}0,044 & 0,115 & 0,101 & 0,170 \\ 0,044 & 0,173 & 0,067 & 0,170 \\ 0,044 & 0,057 & 0,101 & 0,170 \\ 0,044 & 0,173 & 0,101 & 0,255 \\ 0,044 & 0,115 & 0,067 & 0,085\end{array}\right]$

Tabel 3.4 Max dan Min
Tabel 3.5 Perangkingan

\begin{tabular}{|c|c|c|c|}
\hline $\begin{array}{c}\text { Alter } \\
\text { natif }\end{array}$ & $\begin{array}{c}\text { Max }(\mathrm{C} 1+\mathrm{C} 2+ \\
\mathrm{C} 3+\mathrm{C} 4)\end{array}$ & $\begin{array}{c}\text { Minimu } \\
\mathrm{m}\end{array}$ & $\begin{array}{c}\text { Yi }=\text { Max- } \\
\text { Min }\end{array}$ \\
\hline $\mathrm{A} 1$ & 0,43 & 0 & 0,43 \\
\hline $\mathrm{A} 2$ & 0,454 & 0 & 0,454 \\
\hline
\end{tabular}




\begin{tabular}{|c|c|c|c|}
\hline A3 & 0,372 & 0 & 0,372 \\
\hline A4 & 0,573 & 0 & 0,573 \\
\hline A5 & 0,311 & 0 & 0,311 \\
\hline
\end{tabular}

\begin{tabular}{|c|c|c|}
\hline Alternatif & Yi(Max) & Rangking \\
\hline A4 & 0,573 & 1 \\
\hline A2 & 0,454 & 2 \\
\hline A1 & 0,43 & 3 \\
\hline A3 & 0,372 & 4 \\
\hline A5 & 0,311 & 5 \\
\hline
\end{tabular}

\section{Pengerjaan Sistem Pendukung Keputusan Metode SAW}

Membuat matriks keputusan

$$
X\left[\begin{array}{llll}
3 & 2 & 3 & 2 \\
3 & 3 & 2 & 2 \\
3 & 1 & 3 & 2 \\
3 & 3 & 3 & 3 \\
3 & 2 & 2 & 1
\end{array}\right]
$$

Perhitungan Normalisasi dari setiap alternatif.

$$
\begin{aligned}
& \mathrm{R} 11=3 / \max \{3 ; 3 ; 3 ; 3 ; 3\}=3 / 3=1 \\
& \mathrm{R} 21=3 / \max \{3 ; 3 ; 3 ; 3 ; 3\}=3 / 3=1 \\
& \mathrm{R} 31=3 / \max \{3 ; 3 ; 3 ; 3 ; 3\}=3 / 3=1 \\
& \mathrm{R} 41=3 / \max \{3 ; 3 ; 3 ; 3 ; 3\}=3 / 3=1 \\
& \mathrm{R} 51=3 / \max \{3 ; 3 ; 3 ; 3 ; 3\}=3 / 3=1 \\
& \mathrm{R} 12=2 / \max \{2 ; 3 ; 1 ; 3 ; 2\}=2 / 3=0.666 \\
& \mathrm{R} 22=3 / \max \{2 ; 3 ; 1 ; 3 ; 2\}=3 / 3=1 \\
& \mathrm{R} 32=1 / \max \{2 ; 3 ; 1 ; 3 ; 2\}=1 / 3=0.333 \\
& \mathrm{R} 42=3 / \max \{2 ; 3 ; 1 ; 3 ; 2\}=3 / 3=1 \\
& \mathrm{R} 52=2 / \max \{2 ; 3 ; 1 ; 3 ; 2\}=2 / 3=0.666 \\
& \mathrm{R} 13=3 / \max \{3 ; 2 ; 3 ; 3 ; 2\}=3 / 3=1 \\
& \mathrm{R} 23=2 / \max \{3 ; 2 ; 3 ; 3 ; 2\}=2 / 3=0.666 \\
& \mathrm{R} 33=3 / \max \{3 ; 2 ; 3 ; 3 ; 2\}=3 / 3=1 \\
& \mathrm{R} 43=3 / \max \{3 ; 2 ; 3 ; 3 ; 2\}=3 / 3=1 \\
& \mathrm{R} 53=2 / \max \{3 ; 2 ; 3 ; 3 ; 2\}=3 / 3=0.666 \\
& \mathrm{R} 14=2 / \max \{2 ; 2 ; 2 ; 3 ; 1\}=2 / 3=0.666 \\
& \mathrm{R} 24=2 / \max \{2 ; 2 ; 2 ; 3 ; 1\}=2 / 3=0.666 \\
& \mathrm{R} 34=2 / \max \{2 ; 2 ; 2 ; 3 ; 1\}=2 / 3=0.666 \\
& \mathrm{R} 44=3 / \max \{2 ; 2 ; 2 ; 3 ; 1\}=3 / 3=1 \\
& \mathrm{R} 54=1 / \max \{2 ; 2 ; 2 ; 3 ; 1\}=1 / 3=0.333
\end{aligned}
$$

Dari perhitungan diatas diperoleh matriks normalisasi sebagai berikut:

$\mathrm{R}\left[\begin{array}{cccc}1 & 0,666 & 1 & 0,666 \\ 1 & 1 & 0,666 & 0,666 \\ 1 & 0,333 & 1 & 0,666 \\ 1 & 1 & 1 & 1 \\ 1 & 0,666 & 0,666 & 0,333\end{array}\right]$


Selanjutnya melakukan perangkingan dengan rumus:

$\mathrm{Vi}=\sum_{j=1}^{n} w_{j} r_{i j}$

Dengan nilai: $\mathrm{W} 1=0.1, \mathrm{~W} 2=0.3, \mathrm{~W} 3=0.2, \mathrm{~W} 4=0.4$

Maka hasil yang diperoleh sebagai berikut:

$\mathrm{V} 1=(0.1 * 1)+(0.3 * 0.666)+(0.2 * 1)+(0.4 * 0.666)=0.765$

$\mathrm{V} 2=(0.1 * 1)+(0.3 * 1)+(0.2 * 0.666)+(0.4 * 0.666)=0.799$

$\mathrm{V} 3=(0.1 * 1)+(0.3 * 0.333)+(0.2 * 1)+(0.4 * 0.666)=0.665$

$\mathrm{V} 4=(0.1 * 1)+(0.3 * 1)+(0.2 * 1)+(0.4 * 1)=1$

$\mathrm{V} 5=(0.1 * 1)+(0.3 * 0.666)+(0.2 * 0.666)+(0.4 * 0.333)=0.565$

Dari hasil perhitungan di atas didapatkan nilai yang tertinggi yaitu V4, jadi V4 akan dipilih sebagai bibit jambu madu terbaik sesuai dengan kriteria yang telah dibuat. Berikut merupakan tabel hasil perangkingan.

Tabel 4.9 Perangkingan Metode SAW

\begin{tabular}{|c|c|c|}
\hline Alternatif & Nilai & Rangking \\
\hline V4 & 1 & 1 \\
\hline V2 & 0,799 & 2 \\
\hline V1 & 0,765 & 3 \\
\hline V3 & 0,665 & 4 \\
\hline V5 & 0,565 & 5 \\
\hline
\end{tabular}

\section{Kesimpulan}

1. Berdasarkan hasil penelitian dalam menerapkan Sistem Pendukung Keputusan menggunakan metode MOORA dan SAW ini dapat membantu pengguna dalam menentukan pemilihan bibit jambu madu.

2. Hasil perangkingan menggunakan Metode MOORA dan SAW mendapatkan rangking yang sama yaitu Sampel 4 (V4) yang mendapatkan rangking 1.

3. Agar dapat memiliki hasil yang akurat dapat menggunakan banyak sampel data bibit jambu madu.

\section{DAFTAR PUSTAKA}

[1] T. Noviyanti, "Sistem Penunjang Keputusan Dalam Penerimaan Beasiswa Ppa Menggunakan Metode Analytic Hierarchy Process (Ahp) (Studi Kasus: Universitas Gunadarma)," J. Ilm. Teknol. dan Rekayasa, vol. 24, no. 1, pp. 35-45, 2019.

[2] A. Mu, "Sistem Pendukung Keputusan Dalam Pemilihan Pergururan Tinggi Terbaik Dengan Menggunakan Metode SAW (Simple Additive Weighting)," J. Chem. Inf. Model., vol. 53, no. 9, pp. 1689-1699, 2019.

[3] K. N. A. Nur, S. R. Andani, and P. Poningsih, "Sistem Pendukung Keputusan Pemilihan Operator Seluler Menggunakan Metode Multi-Objective Optimization on the Basis of Ratio Analysis (Moora)," KOMIK (Konferensi Nas. Teknol. Inf. dan Komputer), vol. 2, no. 1, pp. 61-65, 2018.

[4] S. W. Pasaribu, E. Rajagukguk, M. Sitanggang, R. Rahim, and L. A. Abdillah, "Implementasi Multi-Objective Optimization On The Basis Of Ratio Analysis ( MOORA ) Untuk Menentukan Kualitas Buah Mangga Terbaik," JURIKOM (Jurnal Ris. Komputer), vol. 5, no. 1, pp. 50-55, 2018.

[5] Suyono, R. Wati, and Y. Pratama, "Sistem Pendukung Keputusan Menentukan Kualitas Bibit Pala Menggunakan Metode Saw (Simple Additive Weighting)," Manag. Sist. Inf. dan Teknol., vol. 07, no. 1, p. 1, 2017.

[6] N. C. Resti, "Penerapan Metode Simple Additive Weighting (SAW) pada Sistem Pendukung Keputusan Pemilihan Lokasi untuk Cabang Baru Toko Pakan UD. Indo Multi Fish," Intensif, vol. 1, no. 2, p. 102, 2017. 